\title{
Risk Factors which affect the change of Antibiotics in Neonatal Pneumonia observed in A Tertiary Care Hospital
}

\author{
M M Z Islam ', M M Hossain ${ }^{2}$, M A M Mamun ${ }^{3}$, S Mahmud ${ }^{4}$, B H N Yasmeen ${ }^{5}$
}

${ }^{1}$ Dr. Mirza Md. Ziaul Islam Assistant Professor Dhaka Shishu Hospital, Dhaka

2 Prof. Dr. M Monir Hossain Head, Dept. of Critical Care Dhaka Shishu Hospital, Dhaka

3 Dr. Md. Abdullah AI Mamun Medical Officer Dept. of Neonatology Dhaka Shishu Hospital, Dhaka

4 Dr. Salahuddin Mahmud Assistant Professor Dhaka Shishu Hospital, Dhaka

5 Dr B H Nazma Yasmeen Associate Professor Dept of Paediatrics Northern International Medical College

Correspondence

Dr. Mirza Md. Ziaul Islam Assistant Professor Dhaka Shishu Hospital, Dhaka

E-mail : mirzamd.ziaulislam@yahoo.com

\begin{abstract}
Background : Neonatal pneumonia accounts for significant morbidity and mortality specially in developing countries like Bangladesh. Perhaps because of its etiologic complexity, pneumomia in neonates has been relatively refractory to reduce its severity and improve the prognosis. Re- evaluation of the antibiotic therapy is necessary in patients to have at 48 hours after diagnosis. Physician should suspect inappropriate antibiotic therapy in cases with persistence of symptoms.

Objective: This study was carried out to find the risk factors (clinical and laboratory parameters) which affect the change of antibiotic in neonatal pneumonia and its effect on morbidity and mortality .

Methodology: This prospective observational study was conducted in Dhaka Shishu (children) Hospital from July 2009 to June 2010. A total of 115 neonates who met the inclusion criteria were enrolled in the study. The neonates were managed using a standard protocol. They were closely followed up to see the outcome with the change in antibiotics.
\end{abstract}

Results : Total 115 neonates were admitted with mean age $16.2 \pm 5.9$ days, mean weight $2857.6 \pm 580.6 \mathrm{gm}, 58 \%$ were male \& $42 \%$ female, $26 \%$ were preterm \& $74 \%$ were term and majority of them $(73 \%)$ were from rural areas. Among the neonates, $36(31,3 \%)$ needed a change in antibiotics. Fever, positive CRP, low $\mathrm{O}_{2}$ saturation, low $\mathrm{PaO}_{2}$, high alveolar-arterial $\mathrm{O}_{2}$ gradient, low arterial-alveloar $\mathrm{O}_{2}$ tension and low pH were significantly associated with change in antibiotics.

Conclusion : Addressing the clinical and laboratory parameters appropriately the change in antibiotic in selected cases can reduce both morbidity and mortality of neonates with pneumonia.

Key Words: Neonatal pneumonia, risk factors, clinical \& laboratory parameters.

\section{Introduction}

Pneumonia is an important cause of neonatal infection and accounts for significant morbidity and mortality especially in developing countries where the World Health Organization estimates that 800,000 neonatal deaths occur each year from acute respiratory infections mostly pneumona ${ }^{1}$. The greatest risk of death from pneumonia in childhood is in the neonatal period ${ }^{2}$.

Although pneumonia is an important cause of morbidity among neonates, it remains a difficult disease to identify and treat ${ }^{3}$. Clinical manifestations are often non-specific, sharing respiratory and hemodyanamic signs with a host of non-inflammatory process ${ }^{4}$.

In general, neonates with the diagnosis of pneumonia in the newborn nursery receive broad spectrum antibiotics, usually ampicillin and gentamicin ${ }^{5}$.

Determining the duration of antibiotic therapy for neonatal pneumonia poses a dilemma for the clinician; the infection must be adequately treated, for avoiding needless prolong hospitalization and exposure to antibiotics. The antibiotics were changed if the patients did not improve after 48 hours of initiation of treatment or deteriorated in the form of increasing chest in drawing or worsening hypoxaemia ${ }^{6}$.

Therefore, there is a need to evaluate the clinical and laboratory parameters which affect the need for change of antibiotics during the management of neonatal pneumonia and may aid in reducing morbidity and mortality in neonates.

\section{Materials and Methods}

This was a prospective observational study carried out in Dhaka Shishu (Children) Hospital from July 2009 to June 2010. 115 neonates were selected following inclusion criteria. Pneumonia was diagnosed when neonates were presented with any of the respiratory symptoms like rapid, noisy or difficult breathing, respiratory rate ${ }^{3} 60 / \mathrm{min}$, severe chest in drawing, grunting or cyanosis, cough, if age of neonates $<72$ hours with maternal fever, foul smelling liqueur, prolonged rupture of membrane (PROM) and any of radiographical finding of chest like nodular or any patchy opacity or sub-lobar consolidation.

Neonates having congenital heart disease, congenital malformation of respiratory or $\mathrm{Gl}$ tract, meconium aspiration syndrome, TTN, RDS were excluded from the study.

A structured questionnaire was used for recording all the information's. After taking written consent, all neonates who full filled the inclusion criteria were evaluated in a calm and quiet state. Respiratory rate (RR) for 1 minute was recorded. Poorfeeding/sucking, lethargy, poor reflexes, hypo or hyperthermia, abdominal distension, prolonged capillary refill time (CRT $>3 \mathrm{sec})$, heart rate (HR), grunting, cyanosis were recorded by examining the neonates.

Following investigations were done at the time of enrollment: $C B C, C R P, B l o o d C / S$, measurement of $\mathrm{FiO}_{2}, \mathrm{O}_{2}$-saturation by pulse oximetry, Alveolar- 
arterial oxygen gradient $\left(\mathrm{PAO}_{2}-\mathrm{PaO}_{2}\right)$ and arterial- alveolar Oxygen tension ratio $\left(\mathrm{PaO}_{2} / \mathrm{PAO}_{2}\right)$ were calculated and $\mathrm{CXR}$ Daily follow up like $\mathrm{RR}, \mathrm{HR}$, temp., $\mathrm{SPO}_{2}$, cyanosis were observed and change in antibiotic was done when the clinical condition deteriorated or did not improve after 48 hours of treatment. All neonates were followed up to outcome.

Informed written consent was taken from guardian of every single patient.

Data analysis was done by software SPSS 16 version.

\section{Results}

In this study 115 neonates hospitalized with pneumonia were selected according to inclusion criteria during the study period from July 2009 to J une 2010. The findings from the data analysis are documented below.

\section{Table -I : Demographic characteristics of study patients}

\begin{tabular}{lccc} 
& & No. of Neonate & Percent (\%) \\
Age group & $1-7$ days & 11 & 9.6 \\
& $8-12$ days & 24 & 20.9 \\
& $13-18$ days & 31 & 27.0 \\
Mean \pm SD & $19-28$ days & 49 & 42.6 \\
Sex & $16.2 \pm 5.9$ & \multicolumn{2}{c}{ Range 03-27 days } \\
& Male & 67 & 58 \\
Weight in gm & Female & 48 & 42.0 \\
& $1700-2500 \mathrm{gm}$ & 30 & 26.1 \\
& $2501-3000 \mathrm{gm}$ & 43 & 37.4 \\
Mean \pm SD & $3001-3500 \mathrm{gm}$ & 29 & 25.2 \\
Gestational age & $>3500 \mathrm{gm}$ & 13 & 11.3 \\
& $2857.6 \pm 580.6$ & Range $1785-4500 \mathrm{gm}$ & \\
& Preterm & 31 & 26 \\
& Term & 84 & 74
\end{tabular}

The mean age of the neonates was $16.2 \pm 5.9$ days with majority of them were older than 7 days, male neonates were $58 \%$ and female were $42 \%$ with male $\&$ female ratio of $1.38: 1$. Mean weight was 2857.6 $\pm 587.6 \mathrm{gm}$ and $26.1 \%$ of them were with low birth weight. Twenty six percent of the neonates were preterm (Table 1).

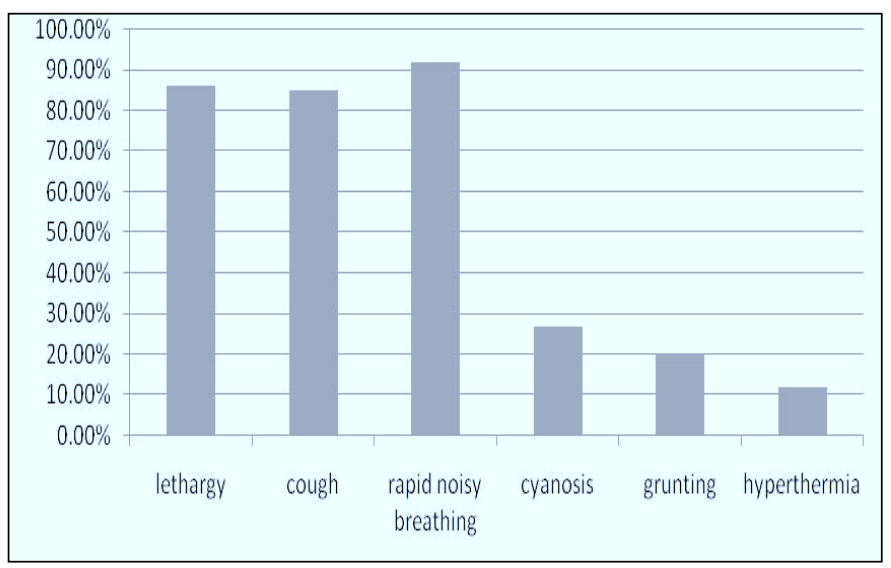

Fig. 1: Presenting complaints of pneumonia cases (multiple response)

The presenting features of the patients (multiple response) were mostly rapid noisy breathing $(92.17 \%, 106$ pts), lethargy $(86.08 \%, 99$ pts), cough $(85.22 \%, 98$ pts), cyanosis $(26.95 \%, 31$ pts), grunting $(20 \%, 23$ pts), hyperthermia (12.17\%, 14 pts).

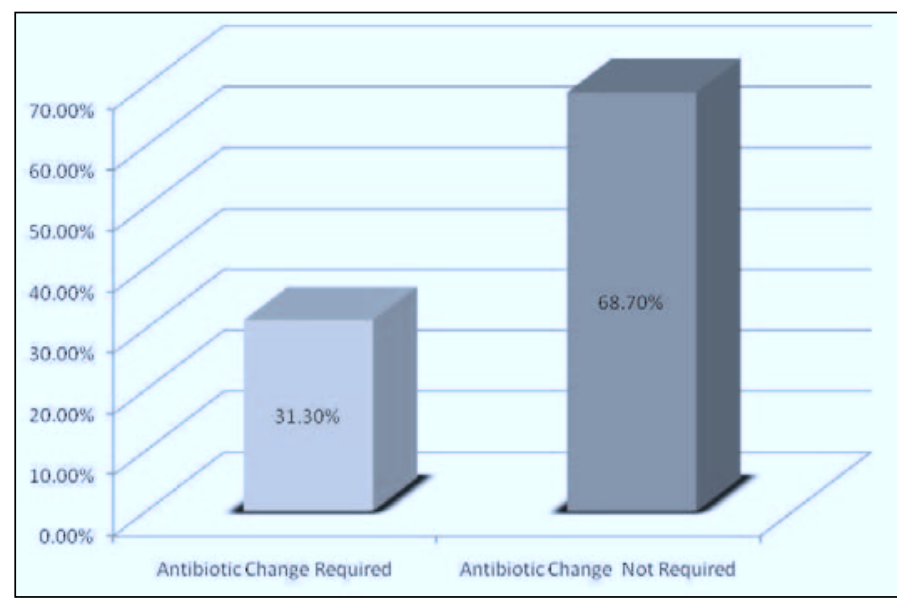

Fig.-2: Proportion of patients with outcome variable

Antibiotic change was required in 36 (31.3\%) patients.

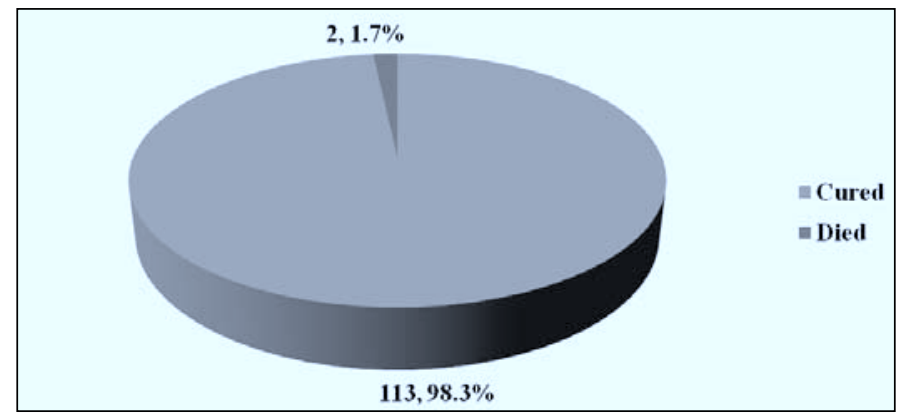

Figure 3 : Outcome of neonates with pneumonia.

Of the 115 neonates admitted with pneumonia, 113 patients (98.3\%) were cured and 2 patients (1.7\%) died.

Table. II Laboratory parameters of the patients

$\begin{array}{llcc}\text { Investigations } & \text { Number } & \% \\ \text { Blood film } & \text { Normocytic Normochromic } & 75 & 65.2 \\ & \text { Macrocytic Normochromic } & 17 & 14.8 \\ \text { Chest X-ray } & \text { Others } & 23 & 20.0 \\ & \text { Normal } & 03 & 2.6 \\ & \text { Nodular Coarse patchy opacity } & 55 & 47.8 \\ & \text { Diffuse haziness Granularity } & 54 & 47.0 \\ & \text { Sub lobar consolidation } & 02 & 1.7 \\ \text { Blood culture } & \text { Non specific pul infection } & 01 & 0.9 \\ & \text { No growth } & 115 & 100 \\ \text { Arterial Blood gas } & \text { Growth } & 00 & 00 \\ \text { analysis } & \text { Normal } & 103 & 89.5 \\ \text { CRP } & \text { Respiratory acidosis } & 12 & 10.5 \\ & \text { Positive } & 56 & 48.7 \\ & \text { Negative } & 59 & 51.3\end{array}$

Blood film showed normocytic normochromic picture in $65.2 \%$, macrocytic normochromic $14.8 \%$, others $20 \%$, chest X-ray showed 
normal in $2.6 \%$, nodular coarse patchy opacity in $47.8 \%$, diffuse haziness or granularity in $47 \%$, sub lobar consolidation in $1.7 \%$. Blood culture showed no growth in any samples. Arterial blood gas analysis was normal in $89.5 \%$ and respiratory acidosis in $10.5 \%$, CRP was positive in $48.7 \%$ and negative in $51.3 \%$.

Table. III: Association between of change of antibiotics and clinical parameters.

\begin{tabular}{|c|c|c|c|c|c|c|}
\hline & & Change in a & antibiotic & & & \\
\hline Clinical parame & & $\begin{array}{l}\text { Antibiotic } \\
\text { changed }\end{array}$ & $\begin{array}{l}\text { Antibiotic } \\
\text { not change }\end{array}$ & Total & Relative Risk & $p$ va \\
\hline Cough & Yes & 80 & 18 & 98 & 1.36 & 0.73 \\
\hline & No & 13 & 04 & 17 & $(0.39-4.68)$ & \\
\hline Rapid noisy or & Yes & 85 & 21 & 106 & 0.56 & 1.0 \\
\hline difficult breathing & No & 08 & 01 & 09 & $(0.06-4.27)$ & \\
\hline Grunting & Yes & 19 & 04 & 23 & 1.16 & 1.0 \\
\hline & No & 74 & 18 & 92 & $(0.32-4.59)$ & \\
\hline Cyanosis & Yes & 25 & 06 & 31 & 1.06 & 0.87 \\
\hline & No & 67 & 17 & 84 & $(0.83-1.24)$ & \\
\hline Lethargy & Yes & 71 & 28 & 99 & 1.97 & 0.26 \\
\hline & No & 09 & 07 & 16 & $(0.67-5.80)$ & \\
\hline Fever & Yes & 05 & 09 & 14 & 0.08 & 0.01 \\
\hline & No & 87 & 14 & 101 & $(0.02-0.30)$ & \\
\hline
\end{tabular}

Fever was significantly associated with change in antibiotics.

Table: IV: Association between change in antibiotic and CRP CRP

\begin{tabular}{lccccc} 
& \multicolumn{2}{c}{ Change in antibiotic } & Total & Relative Risk & p value \\
& Yes & No & & & \\
Positive & 15 & 41 & 56 & 3.32 & 0.02 \\
& & & & $(1.15-9.05)$ & \\
Negative & 06 & 53 & 59 & & \\
Total & 21 & 94 & 115 & &
\end{tabular}

Positive CRP was significantly associated with change in antibiotic.

Table V: Association between changes in antibiotic and blood count Change of antibiotic

$\mathrm{p}$

Yes

No

$\begin{array}{lccccc} & \text { Mean } & ( \pm S D) & \text { Mean } & ( \pm S D) & \\ \mathrm{Hb} \% & 13.7 & ( \pm 01.6) & 14.2 & ( \pm 0.9) & 0.11 \\ \mathrm{TLC} & 11288.1 & ( \pm 3426.4) & 11801.6 & ( \pm 3173.8) & 0.51 \\ \text { Platelet } & 289190.5 & ( \pm 57117.9) & 284956.5 & ( \pm 66002.2) & 0.78\end{array}$

In this study, no association was found between blood count and change in antibiotic.
Table VI : Association between change in antibiotics and arterial blood gas analysis, alveolar-arterial oxygen gradient, arterialalveolar oxygen tension.

Change of antibiotic

$$
\mathrm{p}
$$

Yes

No

\begin{tabular}{|c|c|c|c|c|c|}
\hline & Mean & $( \pm S D)$ & Mean & $( \pm S D)$ & \\
\hline $\mathrm{pH}$ & 7.35 & $( \pm 0.05)$ & 7.3.8 & $( \pm 0.03)$ & 0.002 \\
\hline $\mathrm{O}_{2}$ Saturation & 90.1 & $( \pm 7.2)$ & 92.7 & $( \pm 2.3)$ & 0.04 \\
\hline $\mathrm{PaO}_{2}$ & 103.4 & $( \pm 1.1)$ & 98.6 & $( \pm 19.2)$ & 0.03 \\
\hline Alveolar arterial & 13.5 & $( \pm 3.4)$ & 14.9 & $( \pm 2.4)$ & 0.02 \\
\hline \multicolumn{6}{|l|}{ oxygen gradient } \\
\hline Arterial alveolar & 0.8 & $( \pm 0.2)$ & 0.9 & $( \pm 0.02)$ & 0.01 \\
\hline \multicolumn{6}{|l|}{ oxygen tension } \\
\hline \multicolumn{6}{|c|}{ Arterial Blood gas analysis } \\
\hline $\mathrm{PO}_{2}$ & 84.8 & $( \pm 15.6)$ & 87.3 & $( \pm 7.5)$ & 0.27 \\
\hline
\end{tabular}

The factors which significantly associated with change in antibiotics were low $\mathrm{O}_{2}$-saturation, low $\mathrm{PaO}_{2}$, high alveolar-arterial $\mathrm{O}_{2}$ gradient, low arterial-alveolar oxygen tension and low $\mathrm{pH}$.

\section{Discussion}

Pneumonia is an important cause of neonatal morbidity and mortality. Besides taking preventing measures to decrease the incidence of neonatal pneumonia it is utmost important to predict the factors which are associated with outcome of the pneumonia in hospitalized neonates so that appropriate management can be administered in order to reduce the morbidity and mortality in neonates.

In this study, the mean age at presentation was $16.23 \pm 5.91$ days which is comparable to a study ${ }^{5}$ in the United States in which the median age was 18.9 days (SD \pm 4.6 ). In another study ${ }^{7}$ it was shown that the mean age at presentation was also within 2 weeks. Male patients $(58 \%)$ and female (42\%) which is comparable to a study in Bangladesh. ${ }^{8}$ The mean weight in this study was $2870.58 \pm 580.59 \mathrm{gm}$ which is comparable to a study in Bangladesh. ${ }^{8}$

In our study chest X-ray findings were nodular coarse patchy opacity in $47.6 \%$, diffuse haziness in $46.5 \%$, sublobar consolidation in $2 \%$, other non specific finding in $1 \%$ and in $3 \%$ cases were normal. Benjamin G described chest $\mathrm{X}$-ray finding as diffuse reticular nodular appearance with focal or coarse densities ${ }^{9}$ which is comparable with our study.

In another study by Mathur $\mathrm{NB}^{10}$ et al, chest X-ray finding were alveolar infiltrates in $44.6 \%$ cases, sub-lobar consolidation in $17.4 \%$, lobar consolidation in $9.7 \%$, diffuse haziness in $11.6 \%$, opacity with reticulogranular pattern in $1.9 \%$ and clear in $14.5 \%$.

Blood culture was negative in all cases of our study which is comparable with $\mathrm{T}$. Duke described that bacterial isolation in the WHO study in Kenya showed that majority cases were not associated with bacteremia. ${ }^{5}$ In another large study it became evident that routine surveillance culture contribute little to the prediction and management of pneumonia and may be even misleading. ${ }^{5}$ 
In this study, 36 patients (31.3\%) required change in antibiotic due to deterioration of clinical condition and certain clinical and laboratory parameter which included fever, positive CRP, decreased oxygen saturation, increase alveolar-arterial oxygen gradient, low arterialalveolar oxygen tension, abnormal pH. Duke et $\mathrm{al}^{1}$ described antibiotic change in neonatal pneumonia in different countries as 20\% in Kenya, $24 \%$ in India, $43 \%$ in Pakistan due to first line antibiotic treatment failure which is comparable to this study. In another study, it was evident that pneumonia should be treated according to the unit's antibiotic policy and reevaluation is necessary in children who continue to have unresolved symptoms or fever at 48 hours after diagnosis. In these patients, physicians should suspect inappropriate antibiotic therapy and thus need a change in antibiotic ${ }^{11}$.

\section{Conclusions}

This study concluded that neonates hospitalized with pneumonia presented with fever, positive CRP, decreased $\mathrm{O}_{2}$ saturation, decreased $\mathrm{PO}_{2}$, increased alveolar-arterial $\mathrm{O}_{2}$ gradient and decreased arterialalveolar $\mathrm{O}_{2}$ tension required change in antibiotic during the course of treatment.

\section{References}

1. Duek T. Neonatal pneumonia in developing countries. Arch Dis Child Fetal Neonatal Ed 2005; 90:F21.

2. Hossain MM, Amin MR, Akbar MS. Mortality determinants among critically ill neonates in intensive care unit, DS (child) HJ 2000;16:5-10.

3. Faix RG. University of Utah School of Medicine, in Congenital Pneumonia in eMedicine Pediatrics, 2007.

4. Garenne M, Ronsmans C, Campbell $H$. The magnitude of mortality from acute respiratory infections in children under 5 years in developing Countries. World Health stat 1992; 45:80.

5. Hicky SM, Mc Craken GH Jr. Postnatal bacterial infections. In: Fannwoff AA, Martin RJ, editors. Neonatal Perinatal Medicine: Diseases of the Fetus and Infant, St.Lavis: Mosby; 1997.

6. William D Eagle, Gregory L, Jackson D Ford, et al. Neonatal Pneumonia: Comparison of 4 vs 7 days of Antibiotic therapy in Term \& Near Term Infants. Journal of Perinatology 2000; 20:421-26.

7. Hoffman JA, Mason EO, Schutze GE et al. 2003,"Streptococcal pneumonia infection in the neonates", Pediatrics; 112: 1095-102.

8. Shahana N. Determination of Risk Factors of Neonatal Pneumonia,2009. Dept. of Pediatrics, Dhaka Medical College Hospital, Dhaka.

9. Benjamin Gaston. Pneumonia, Pediatr Rev 2002; 23:133.

10. Mathur NB, Garg K, Kumar S. Respiratory distress in neonates with special reference to Pneumonia, Indian Pediatrics 2002; 39:529-37.

11. British Thoracic Society Standards of Care Committee. British Thoracic Society guidelines for the management of community acquired pneumonia in children. Thorax 2002; 57 (suppll); 1-24. 